\title{
Prevalence of asymmetrical rupture in small earthquakes and its effect on the estimation of stress drop: a systematic investigation in inland Japan
}

Keisuke Yoshida* (1)

\begin{abstract}
Stress drops of small earthquakes have been estimated under the assumption that the rupture propagates symmetrically within a circular fault. However, recent studies have observed directivity effects on seismic waves even for small earthquakes. In this study, rupture directivity was investigated systematically for small-to-moderate-sized earthquakes (M 3.5-5.5) that occurred beneath inland Japan from 2004 to April 2019. Apparent moment rate functions were determined for 1463 earthquakes, and their corner frequencies were inverted for their rupture parameters. The results indicate that most of the analyzed earthquakes (1217 of 1463) are characterized by significantly asymmetrical rupture propagation. The stress drops of the earthquakes estimated by considering asymmetrical rupture propagation were 16.8 $\mathrm{MPa}$, which are almost twice the estimates based on the commonly used symmetrical rupture model. This shows the importance of recognizing the diversity of ruptures, even for small earthquakes, for extracting information about earthquake sources and the Earth's structure. The prevailing rupture directivity can provide useful information on source parameters including the fault size, fault geometry, and rupture velocity of small earthquakes.
\end{abstract}

Keywords: Stress drop, Rupture directivity, Source process, Asymmetrical rupture, Source model, Crustal earthquakes, Stress magnitude, Fault strength

\section{Introduction}

Earthquakes are natural phenomena that redistribute stress and release strain energy accumulated inside the earth (Knopoff 1958). The average decrease in shear stress along the earthquake fault is referred to as the static stress drop; this is one of the key parameters describing the earthquake source.

It is difficult to reliably estimate the stress drop of small earthquakes. The dominant frequency of the waveform is used for the estimation of stress drop based on simple symmetrical circular source models (Brune 1970; Sato and Hirasawa 1973; Madariaga 1976). However, if the real source process is asymmetrical or has a significant

*Correspondence: keisuke.yoshida.d7@tohoku.ac.jp Research Center for Prediction of Earthquakes and Volcanic Eruptions, Graduate School of Science, Tohoku University, 6-6 Aza-Aoba, Aramaki, Aoba-ku, Sendai 980-8578, Japan directivity, the assumption of symmetrical rupture evolution can lead to a large error in the estimated stress drop (Kaneko and Shearer 2015; Yoshida et al. 2019a). It has been reported that a significant proportion of large earthquake ruptures are predominantly unilateral (McGuire et al. 2002). Recently, directivity effects have been observed in seismic waves for moderate-sized (e.g., Abercrombie et al. 2017; Boatwright 2007; McGuire 2004) and even smaller earthquakes (e.g., Kane et al. 2013; Folesky et al. 2016; Yamada et al. 2005; Yoshida et al. 2019a). Rupture directivity is of interest itself, but is also important for unbiased estimation of other geophysical parameters, including stress drop.

This study systematically investigated rupture directivity and stress drop for small-to-moderate-sized earthquakes (Mw 3.3-5.5) in inland Japan. The results indicate that many of the analyzed earthquakes are characterized 
by asymmetrical rupture propagation, and also show that stress drops are systematically underestimated if the symmetrical rupture propagation model is applied to the data.

\section{Data and methods}

The present study estimated the rupture parameters for shallow inland earthquakes $(z<40 \mathrm{~km})$ whose moment tensor was listed in the F-net catalog (Fukuyama et al. 1998). The data period is from 2004 to April 2019. The analysis was restricted to events beneath the land having good seismic station azimuthal coverage (Fig. 1b). The seismic network is composed of stations from the Japan Meteorological Agency (JMA), national Universities, Hinet, F-net, and V-net of the National Research Institute for Earth Science and Disaster Resilience (NIED). The total number of earthquakes studied was 2712 (Fig. 1a).

For estimation of rupture directivity and stress drop, a method similar to Yoshida et al. (2019a) was used as detailed in "A generalized rupture model" section. Under this approach, the durations of apparent moment rate functions (AMRFs) were inverted for rupture parameters. Then, the AMRFs and their corner frequencies were determined for each earthquake ("Determination of apparent moment rate function and corner frequency" section), and the rupture directivities and stress drops were estimated based on the general rupture model ("Estimation of rupture directivity and stress drop" section).

\section{A generalized rupture model}

The rupture directivity and stress drop were estimated for each earthquake by comparing observed AMRFs with those computed from a source model incorporating the asymmetrical rupture. It is desirable to estimate the source parameters without imposing any assumptions on the source process. However, seismic waveform data are only recorded near the Earth's surface and they lack necessary high frequencies due to low-pass filters, low sampling rates, or noise. These make it almost impossible to uniquely determine the source parameters of small earthquakes (e.g., McGuire and Kaneko 2018) without imposing some physical constraints. The present study, therefore, used the elliptical asymmetrical rupture model of Dong and Papageorgiou (2003) with a few additional constraints. The model is a generalized version of the self-similar symmetrical circular source model of Sato

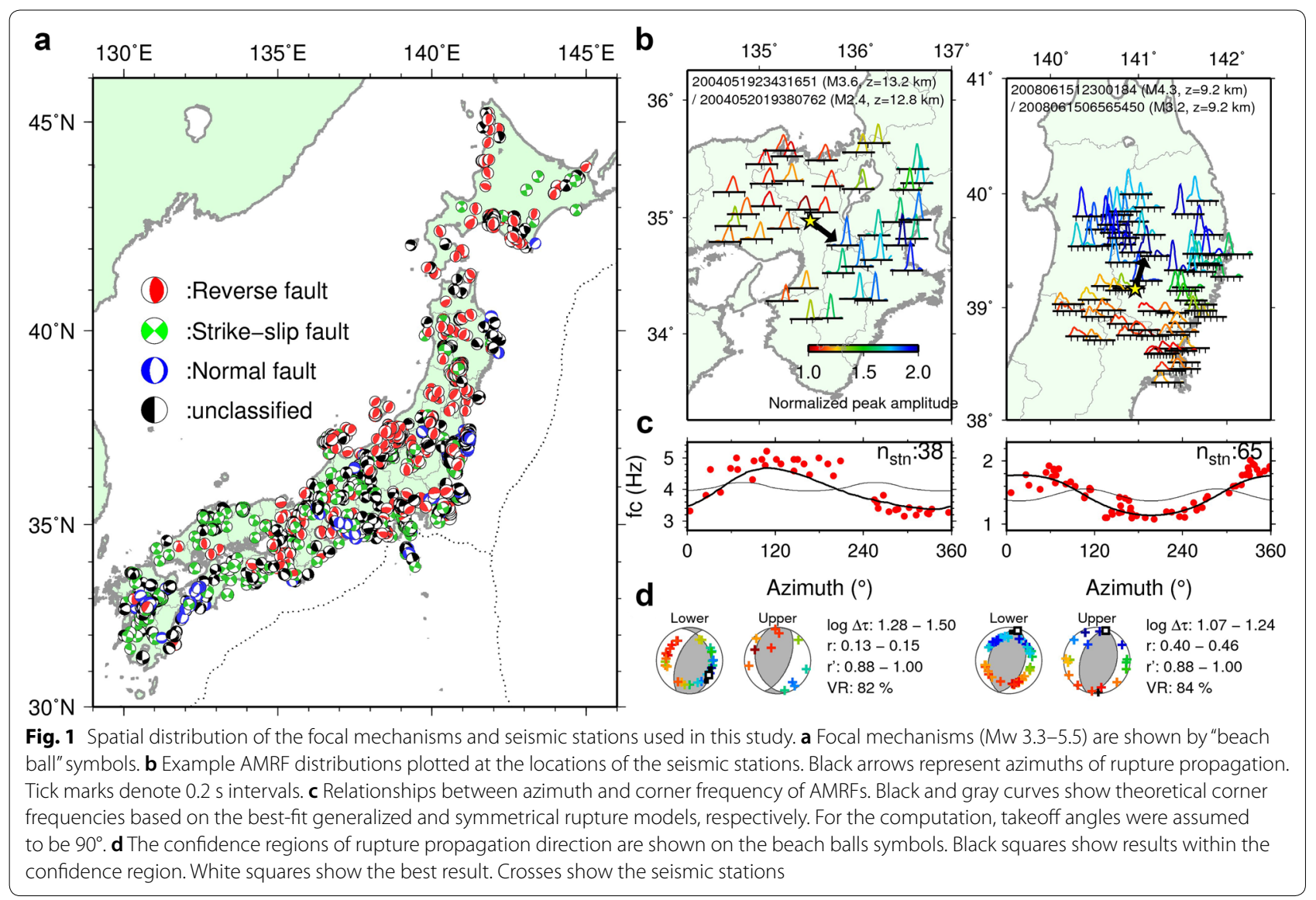


and Hirasawa (1973) based on Eshelby's (1957) static solution for the crack.

In this study, an earthquake rupture is approximated by the expansion of a circular fault with final radius $r$. Instead of assuming ruptures always initiate at the center of the final fault, as in Sato and Hirasawa (1973), ruptures are allowed to initiate at an arbitrary point inside the circle (Fig. 2a-c). The self-similarly circular front expands with a constant velocity $V_{\mathrm{r}}$, while the center of the rupture front moves to the circle center with a constant velocity of $r^{\prime} V_{\mathrm{r}}$. Here, $r^{\prime}$ is the relative distance of the initiation point measured from the center to the final fault radius $r$. Thus, the rupture front propagates with a maximum velocity $V_{\mathrm{rmax}}=\left(1+r^{\prime}\right) V_{\mathrm{r}}$ toward the center of the fault; I assumed that $V_{\mathrm{rmax}} / V_{\mathrm{S}}=0.9$, where $V_{\mathrm{S}}$ is $\mathrm{S}$-wave velocity. The slip stops instantaneously when $t=r / V_{\mathrm{r}}$. While the present model corresponds to the symmetrical circular rupture model of Sato and Hirasawa (1973) when $r^{\prime}=0$, it can also express asymmetrical ruptures when $r^{\prime}>0$. The present study hereafter refers to the present model as the generalized circular rupture model to contrast it with the commonly used symmetrical rupture model.

Figure 2 shows examples of computed AMRFs for three different rupture processes $\left(r^{\prime}=0,0.4,0.8\right)$ along a nearly vertical strike-slip fault (strike of $0^{\circ}$ and dip of $80^{\circ}$ ). The source duration and the moment magnitude were assumed to be the same for the three models $(0.5 \mathrm{~s}$ and Mw 5.0, respectively). The rupture propagates toward the south in the asymmetrical rupture model cases $\left(r^{\prime}=0.8,0.4\right.$; Fig. 2a, b), which causes strong directivity effects on the AMRF durations (Fig. $2 \mathrm{~d}-\mathrm{k}$ ). Note that even a symmetrical rupture produces directional dependences of AMRF durations (Fig. 2l-o), although the directional pattern is different from the asymmetrical rupture (Sato and Hirasawa 1973). Although the source sizes, and thus the stress drops, are considerably different in the three models, the average source corner frequencies are similar $(\sim 1 \mathrm{~Hz})$. The large differences of stress drop (varying from 5.3 to $31.0 \mathrm{MPa}$ ), despite similar average corner

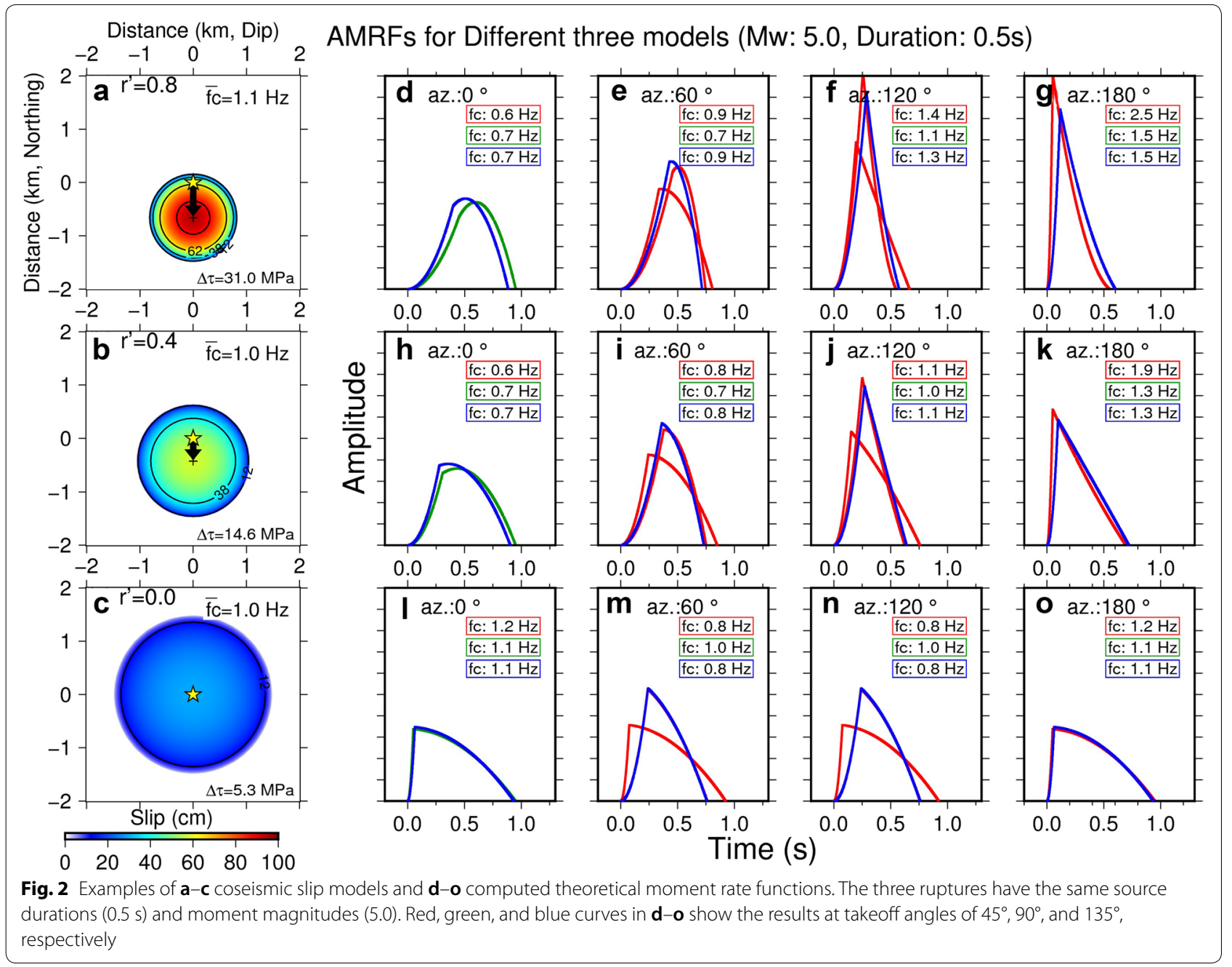


frequencies and the same seismic moments, indicate the importance of modeling not only the average value but also the directional dependency of source duration.

\section{Determination of apparent moment rate function and corner frequency}

The AMRFs were derived using the empirical Green's function (EGF) method (Hartzell 1978) based on the waveforms observed for nearby small earthquakes (EGF events). EGF events satisfy the following two criteria: (1) distance from the target event is $<1.5 \mathrm{~km}$ according to the JMA unified catalog; (2) the magnitude is 1-2 smaller than the target earthquake. Transverse components of direct $\mathrm{S}$-waves were used.

For waveform deconvolution, the present study adopted the iterative time-domain approach developed by Ligorría and Ammon (1999) after Kikuchi and Kanamori (1982). The cut-off frequency of the low-pass filter $\left(f_{1}\right)$ was set to the expected corner frequency when assuming $50 \mathrm{MPa}$ of stress drop in the model of Sato and Hirasawa (1973) with $\frac{\mathrm{Vr}}{\mathrm{Vs}}=0.9$. The cut-off frequency $f_{1}$, which depends on the seismic moment of the target event, was lower than the expected corner frequency of EGF events with stress drop of 0.5 MPa. The low-pass filter effectively removes the effects of source processes of EGF events when the stress drops of the target earthquake and the EGF earthquake are less than $50 \mathrm{MPa}$ and greater than $0.5 \mathrm{MPa}$, respectively. The same low-pass filter was applied to theoretical AMRFs as described later in order not to omit the possibility that the stress drop of the target event is greater than $50 \mathrm{MPa}$. The assumed values of the upper and lower limits of stress drop were validated based on the obtained values of stress drop.

The deconvolution was regarded as successful if the synthetic waveform reproduces more than $80 \%$ of the observed waveform measured in terms of variance reduction. When there were multiple EGF earthquakes for a target event, multiple results were stored for the same stations. Figure $1 \mathrm{~b}$ shows two examples of the spatial distributions of AMRF. AMRFs were obtained from more than 15 different stations for 1463 of the initial 2712 earthquakes, for which rupture directivity was examined. The corner frequency of Andrews (1986) was computed for each AMRF in the time-domain.

\section{Estimation of rupture directivity and stress drop}

A grid-search was performed for the optimal combination of stress drop $(\Delta \tau)$, relative distance of the hypocenter to the fault radius $\left(r^{\prime}\right)$, and orientation of the rupture propagation $(\phi)$ that best explained the observed corner frequencies. The orientation of rupture propagation was grid-searched over the two nodal planes of the focal mechanism. For comparison with the observations, the same low-pass filter was applied to theoretical AMRFs derived using the analytical solution of Dong and Papageorgiou (2003) and the corner frequencies were numerically computed. Depth-dependent values of $V_{S}$ were assumed according to the JMA2001 model (Ueno et al. 2002).

The rupture parameters which minimize function (1) were then obtained.

$$
\operatorname{Var}_{\text {general }}\left(\Delta \tau, r^{\prime}, \phi\right)=\sum_{i=1}^{n}\left(f_{\mathrm{c}}^{\text {general }}\left(\theta_{\mathrm{i}}, \Delta \tau, r^{\prime}, \phi\right)-f_{c i}\right)^{2} / n .
$$

Here, $f_{\mathrm{c} i}$ and $f_{\mathrm{c}}^{\text {general }}$ are, respectively, the observed and computed corner frequencies, $\theta_{i}$ is the orientation of the ray to the $i$ th station, and $n$ is the number of observations. The minimum residual $V_{\text {areneral }}^{\text {best }}$ of Eq. (1) was compared with that given by the symmetrical rupture model $\operatorname{Var}_{\text {sym }}^{\text {best }}$ (the minimum residual under $r^{\prime}=0$ ):

$$
\mathrm{VR}=100\left(1-\frac{\operatorname{Var}_{\text {general }}^{\text {best }}}{\operatorname{Var}_{\text {sym }}^{\text {best }}}\right)
$$

If the rupture is more suitably modeled by a unilateral rupture, VR approaches 100. Search ranges and grid intervals (evenly spaced) of the grid-search are the followings: $\log _{10} \Delta \tau$ is searched from -1 to 2.5 with 200 grids, $r^{\prime}$ from 0.0 to 1.0 with 8 grids, and $\phi$ from $0^{\circ}$ to $180^{\circ}$ with 12 grids.

The confidence ranges were estimated based on the $\chi^{2}$ statistics:

$$
\chi^{2}=\sum_{i=1}^{n} \frac{X_{i}^{2}}{\sigma_{i}^{2}}
$$

where $X_{i}$ is the misfit of a model for $i$ th data, which is assumed to follow the Gaussian distribution, and $\sigma_{i}^{2}$ is the variance. By approximating $\sigma_{i}^{2}$ by Varasym, I computed the value of summed residual at the $95 \%$ confidence limit and estimated the $95 \%$ confidence regions of the rupture parameters. Obtained parameters are regarded as not well-constrained and discarded if the maximum difference between the best-fit solution and the values at the 95\% confidence limits exceeds the following levels: 0.5 for $r^{\prime}, 0.5$ for $\log _{10} \Delta \tau$, and $45^{\circ}$ for $\phi$. The number of wellconstrained estimates thus obtained is 627 for $r^{\prime}, 1164$ for $\Delta \tau$, and 435 for $\phi$.

\section{Results}

By incorporating the effect of asymmetrical rupture propagation, the residuals decreased over $40 \%$ (i.e., VR $>40 \%$ ) for more than $60 \%$ of the target earthquakes (904 of 1463 events) as shown by the frequency distribution in Fig. 3a. This indicates that half of the analyzed 
earthquakes involved non-negligible rupture directivities in their source processes.

To statistically address whether the asymmetrical rupture (i.e., rupture directivity) is required, I used the Akaike information criterion (AIC; Akaike 1974):

$$
\mathrm{AIC}=-2 \ln L+2 m
$$

where $L$ is the maximum likelihood and $m$ is the number of model parameters. I assumed that the measurement errors of the corner frequencies follow a Gaussian distribution such that:

$$
\ln L=-\frac{n}{2} \ln \left(2 \pi s^{2}\right)-\frac{n}{2}
$$

where $s^{2}$ is the mean of the squared residuals. Substituting $m=2$ for the circular symmetrical rupture model and $m=4$ for the generalized rupture model, $\triangle$ AIC was computed as $\triangle \mathrm{AIC}=\mathrm{AIC}_{\text {sym }}-\mathrm{AIC}_{\text {general }}$, where $\mathrm{AIC}_{\text {sym }}$ and $\mathrm{AIC}_{\text {general }}$ are the $\mathrm{AICs}$ of the symmetrical and generalized rupture model, respectively. As a result, 1313 of 1463 earthquakes turned out to have positive $\triangle \mathrm{AICs}$ (Fig. $3 \mathrm{~b}$ ). The $\triangle \mathrm{AIC}$ can be converted into the log-likelihood ratio statistic (e.g., Ogata 1983; Iwata 2002; Iwata and Young 2005):

$$
-2 \ln \frac{L_{\text {sym }}}{L_{\text {general }}}=\Delta \mathrm{AIC}+2 k
$$

where $L_{\text {sym }}$ and $L_{\text {general }}$ are the maximum likelihoods for the symmetrical and generalized rupture models and $k$ is the difference in the number of parameters $(k=2)$. The log-likelihood ratio statistic is expected to follow the Chisquared distribution with $k$ degrees of freedom. If $\triangle \mathrm{AIC}$ is larger than 2, the log-likelihood statistic is larger than 6 , and the significance level of positive $\triangle \mathrm{AIC}$ is greater than approximately $95 \%$. $\triangle \mathrm{AIC}$ is larger than 2 for 1217 of the 1463 earthquakes, indicating that most of the analyzed events significantly prefer the asymmetrical rupture model to the symmetrical model.

Figure 3c shows the frequency distribution of $r^{\prime}$. Rupture initiation points tend to be located at the edge of the fault $\left(r^{\prime} \sim 1\right)$ (Fig. 3c), supporting the conclusion that asymmetrical ruptures prevail.

Figure $3 \mathrm{~d}-\mathrm{f}$ indicates that when the symmetrical model is used, the fault radii and stress drops are systematically

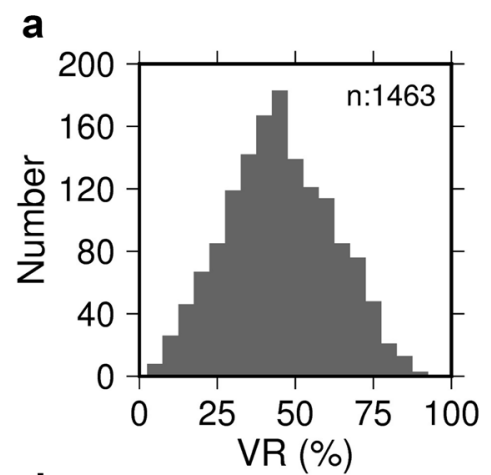

d

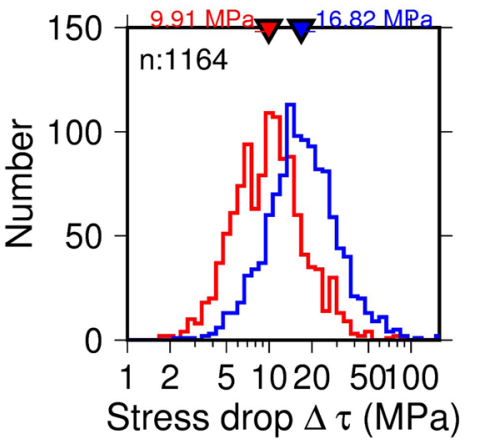

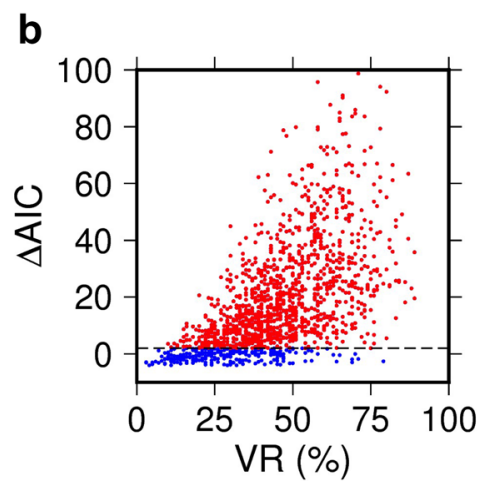

e

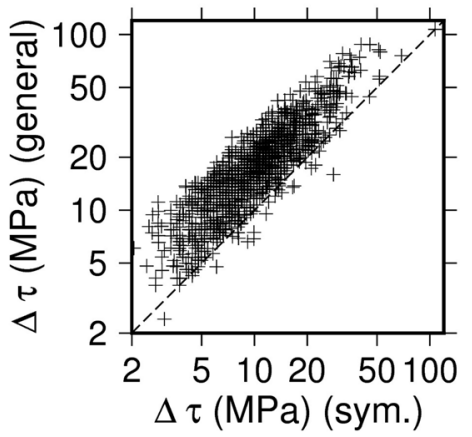

C

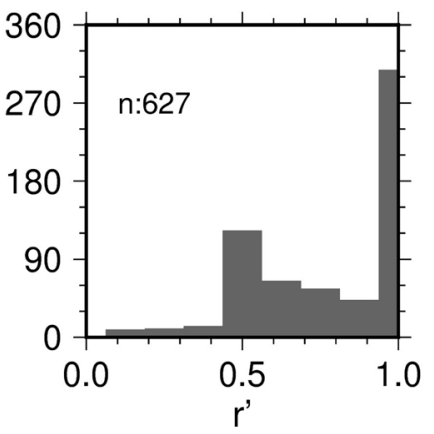

f

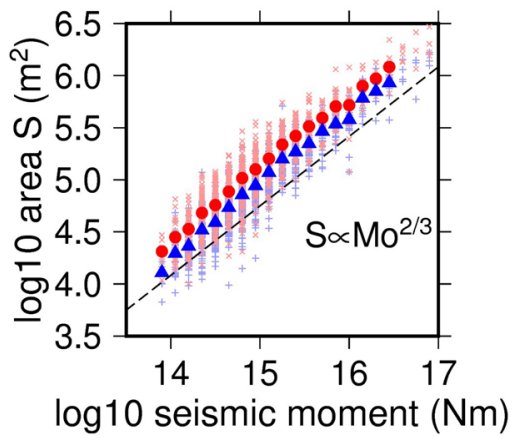

Fig. 3 Results of fitting the asymmetrical rupture model. a Frequency distribution of variance reduction (VR). $\mathbf{b}$ Comparison between VR and $\Delta$ AIC. Red and blue circles show $\triangle A / C$ s greater and less than 2, respectively. $\mathbf{c}$ Frequency distribution of $r^{\prime}$. $\mathbf{d}$ Frequency distribution of stress drop. Blue and red lines indicate the results of the asymmetrical and symmetrical rupture models, respectively. e Comparison between the stress drops based on the asymmetrical and symmetrical rupture models. $\mathbf{f}$ Fault area compared with the seismic moment. Blue and red symbols indicate the results of the asymmetrical and symmetrical rupture model, respectively 
overestimated and underestimated, respectively. It should be noted that these systematic differences are a product of the commonly used assumption of symmetrical rupture rather than the present model settings; As shown in Fig. 2, the symmetrical rupture assumption maximizes estimates of fault radii and thus minimizes estimates of stress drops, for a given source duration and a rupture speed. The median value of stress drop was $16.8 \mathrm{MPa}$ based on the asymmetrical rupture model, but only 9.9 MPa based on the commonly used symmetrical rupture model (Fig. 3d). The obtained values are sufficiently small compared to the assumed upper limit of $50 \mathrm{MPa}$ used for determining the corner frequency of low-pass filter $\left(f_{1}\right)$, which validated the assumption.

Previous studies have estimated the maximum shear stress magnitude in inland Japan to be a few tens of $\mathrm{MPa}$, based on the rotations of stress axis caused by large earthquakes (Yukutake et al. 2007; Yoshida et al. 2014a, 2015a, 2016a, b, 2019b; Matsumoto et al. 2015) or topography (Yoshida et al. 2015b), which is comparable to the present estimate of stress drop. Although the estimate of the absolute value of stress drop depends somehow on the source model, the present results imply that even small earthquakes release a significant proportion of background shear stress on the fault plane.
Alternatively, states of stress in the crust might be highly heterogeneous.

\section{Discussion}

The spatial distribution of stress drop is shown in Fig. 4a. The figure shows the geometrical means, weighted by distance, at each $0.2^{\circ}$-spaced grid node using 1164 wellconstrained stress drops within a $0.6^{\circ}$ distance in both longitude and latitude. The averaged values are shown only when the number of data values was greater than 4 .

The spatial pattern of stress drop is substantially different from that reported by Oth (2013) based on a generalized inversion technique. His results indicate that stress drop is high in western Japan and low in eastern Japan, which is almost opposite to the present result. He found a strong spatial anti-correlation between stress drop and heat flow, suggesting that thermal structure is a primary control factor for stress drop. The major differences in the processes used by Oth (2013) and those of the present study are: (1) Oth (2013) used a symmetrical rupture model, while the present study incorporated asymmetrical rupture propagation; and, (2) Oth (2013) removed the propagation and site effects of seismic waves by estimating them using some assumptions described below, whereas the present study removed them using the EGF approach which is more appropriate for minimizing

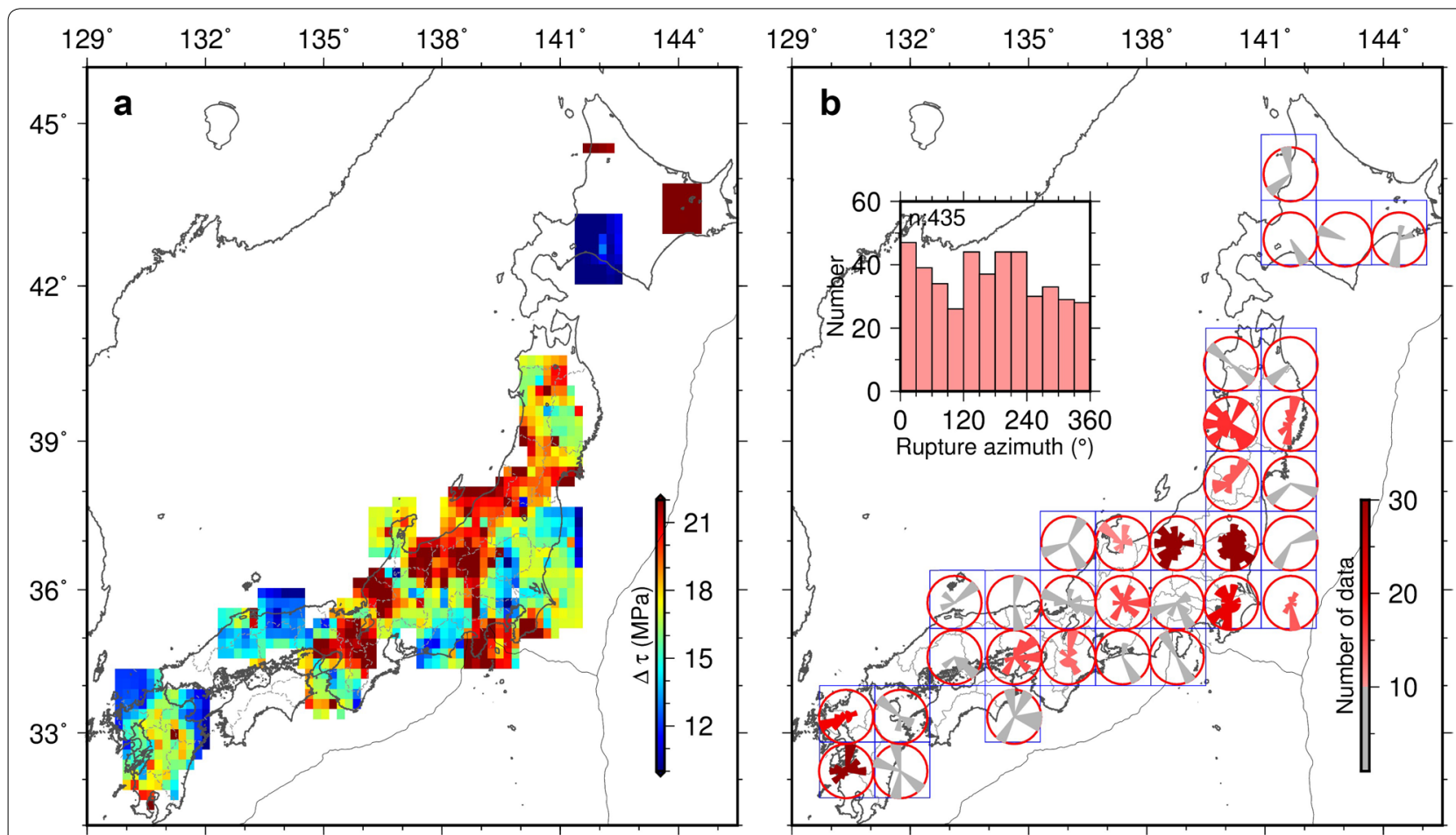

Fig. 4 Results of a spatial distribution of stress drop and $\mathbf{b}$ rupture directivity. In $\mathbf{b}$, the rose diagrams show the relative frequency of rupture directions at the corresponding map locations 
propagation and site effects. The first difference does not seem to be a major cause of the divergent outcomes, because the spatial pattern of stress drop does not change significantly even if the symmetrical rupture model is applied to the data of the present study (Additional file 1: Fig. S1). It can, therefore, be speculated that the second process difference is the main cause of the divergence in results. Oth (2013) assumed that the attenuation structure is spatially homogeneous, and that the average site amplification is zero at the borehole seismic stations in several regional blocks. However, this assumption unlikely holds in Japan (Yoshida et al. 2017). The correlation between stress drop and heat flow suggested by Oth (2013) might be understood if his result actually reflects a correlation of the attenuation structure and site amplification with the temperature structure.

The directions of rupture propagation were generally diverse. However, they seem to have some preferred directions when dividing the results into subregions (Fig. 4b). Recent observations of rupture directivity in small earthquakes also suggest that propagation directions have preferred directions affected by material properties (Kane et al. 2013) and by states of stress and fault strength (Folesky et al. 2016; Yoshida et al. 2019a).

To obtain information about the Earth's structure from seismic waveforms, it is necessary to correctly separate source effects from waveform data. However, the effects of rupture directivity on seismic waveforms have been, at times, disregarded to simplify the problem. The results reported here, showing the predominance of asymmetrical rupture, suggest that ignoring rupture directivity might lead to large estimation errors not only for earthquake sources but also for the Earth's structure. Given that the rupture propagation generally has a preferred direction, the effects of rupture directivity cannot be canceled out, even by averaging the results of many earthquakes. Careful selection of the analyzed frequency range is important to avoid contamination by the effects of rupture diversity. From another perspective, the prevailing rupture directivity might provide useful information on source parameters including the stress drop, fault size, and fault geometry of small earthquakes.

\section{Conclusions}

The present study systematically investigated rupture directivity for small-to-moderate-sized earthquakes ( $M$ 3.5-5.5) beneath inland Japan from 2004 to April 2019.

The result indicates that most of the analyzed earthquakes (1217 of 1463) are characterized by significantly asymmetrical rupture propagation. This suggests that the common symmetrical rupture assumption does not hold for inland Japanese earthquakes and implies that a conventional approach, assuming a symmetrical rupture, to evaluation of source, path, and site effects may not be appropriate. The prevailing rupture directivity might provide useful information on source parameters including the stress drop, fault size, fault geometry, and rupture velocity of small earthquakes. The average stress drop based on an asymmetrical rupture model is about $17 \mathrm{MPa}$, which is almost double the estimate when using the symmetrical rupture model.

In this study, an asymmetrical rupture model based on a static solution of the crack problem was used. However, even this generalized model should not be applied to other types of rupture such as pulse-like ruptures (Heaton 1990) or multiple shocks. The present study also assumed the maximum rupture velocity to be constant $\left(\frac{V_{\mathrm{rmax}}}{V_{\mathrm{S}}}=0.9\right)$, and the fault shape to be circular. It is important to consider the diversity of ruptures, even for small earthquakes, to derive a reliable estimate of earthquake sources and the Earth's structure, which provide important information about seismogenic zones.

\section{Supplementary information}

Supplementary information accompanies this paper at https://doi. org/10.1186/s40562-019-0145-z.

Additional file 1: Fig. S1. Spatial distribution of the stress drop estimated based on the circular symmetrical rupture model.

\section{Acknowledgements}

I deeply thank the editor Kenji Satake and two anonymous reviewers for their constructive comments, which helped to improve the manuscript. I thank the following individuals for providing comments on the first draft of the manuscript: Tatsuhiko Saito, Taka'aki Taira, Ryota Takagi, and Yoshiaki Matsumoto. I am grateful to Takaki Iwata for his helpful comments about the log-likelihood ratio statistic.

\section{Authors' contributions}

Data analysis and manuscript preparation were carried out by KY. The author read and approved the final manuscript.

Funding

This research was supported by JSPS KAKENHI Grant Number JP 17 K1437 (JP26109002).

\section{Availability of data and materials}

This study used hypocenters and P- and S-wave arrival time data reported in the unified catalog of the Japan Meteorological Agency. I used seismograms collected and stored by JMA, national Universities, NIED. The figures were created using GMT (Wessel and Smith 1998).

\section{Competing interests}

The author declares no competing interests.

Received: 27 August 2019 Accepted: 12 November 2019

Published online: 12 December 2019

\section{References}

Abercrombie RE, Poli P, Bannister S (2017) Earthquake directivity, orientation, and stress drop within the subducting plate at the Hikurangi Margin, New Zealand. J Geophys Res Solid Earth 122(76-10):188. https://doi. org/10.1002/2017jb014935 
Akaike H (1974) A new look at the statistical model identification selected papers of Hirotugu Akaike. Springer, Berlin, pp 215-222

Andrews DJ (1986) Objective determination of source parameters and similarity of earthquakes of different size. Earthq Source Mech 37:259-267

Boatwright J (2007) The persistence of directivity in small earthquakes. Bull Seismol Soc Am 97:1850-1861. https://doi.org/10.1785/0120050228

Brune JN (1970) Tectonic stress and the spectra of seismic shear waves from earthquakes. J Geophys Res 75:4997-5009. https://doi.org/10.1029/JB075 i026p04997

Dong G, Papageorgiou AS (2003) On a new class of kinematic models: symmetrical and asymmetrical circular and elliptical cracks. Phys Earth Planet Inter 137:129-151. https://doi.org/10.1016/S0031-9201(03)00012-8

Eshelby JD (1957) The determination of the elastic field of an ellipsoidal inclusion, and related problems. Proc R Soc London Ser A Math Phys Sci 241:376-396

Folesky J, Kummerow J, Shapiro SA et al (2016) Rupture directivity of fluid-induced microseismic events: observations from an enhanced geothermal system. J Geophys Res Solid Earth 121:8034-8047. https:// doi.org/10.1002/2016JB013078

Fukuyama E, Ishida M, Dreger DS, Kawai H (1998) Automated seismic moment tensor determination by using on-line broadband seismic wave-forms. Zisin 2(51):149-156

Hartzell SH (1978) Earthquakes aftershocks as Green's functions. Geophys Res Lett 5:1-4. https://doi.org/10.1029/GL005i001p00001

Heaton TH (1990) Evidence for and implications of self-healing pulses of slip in earthquake rupture. Phys Earth Planet Inter 64:1-20

I wata T (2002) Tidal stress/strain and acoustic emission activity at the Underground Research Laboratory, Canada. Geophys Res Lett 29:30-31

Iwata T, Young RP (2005) Tidal stress/strain and the b-values of acoustic emissions at the Underground Research Laboratory, Canada. Pure Appl Geophys 162:1291-1308

Kane DL, Shearer PM, Goertz-Allmann BP, Vernon FL (2013) Rupture directivity of small earthquakes at Parkfield. J Geophys Res Solid Earth 118:212-221. https://doi.org/10.1029/2012JB009675

Kaneko Y, Shearer PM (2015) Variability of seismic source spectra, estimated stress drop, and radiated energy, derived from cohesive-zone models of symmetrical and asymmetrical circular and elliptical ruptures. J Geophys Res Solid Earth 120:1053-1079. https://doi.org/10.1002/2014JB011642

Kikuchi M, Kanamori H (1982) Inversion of complex body waves. Bull Selsmologmal Socmty Am 72:491-506. https://doi.org/10.1016/00319201(86)90048-8

Knopoff L (1958) Energy release in earthquakes. Geophys J R Astron Soc 1:44-52. https://doi.org/10.1111/j.1365-246X.1958.tb00033.x

Ligorría JP, Ammon CJ (1999) Iterative deconvolution and receiver-function estimation. Bull Seismol Soc Am 89:1395-1400. https://doi.org/10.1016/ S0304-3940(97)00816-1

Madariaga BYR (1976) Dynamics of an expanding circular fault. Bull Seismol Soc Am 66:639-666. https://doi.org/10.1111/j.1461-0248.2009.01352.x

Matsumoto S, Katao H, lio Y (2015) Determining changes in the state of stress associated with an earthquake via combined focal mechanism and moment tensor analysis: application to the 2013 Awaji Island earthquake, Japan. Tectonophysics 649:58-67

McGuire JJ (2004) Estimating finite source properties of small earthquake ruptures. Bull Seismol Soc Am 94:377-393. https://doi.org/10.1785/01200 30091

McGuire JJ, Kaneko Y (2018) Directly estimating earthquake rupture area using second moments to reduce the uncertainty in stress drop. Geophys J Int 214:2224-2235

McGuire JJ, Zhao L, Jordan TH (2002) Predominance of unilateral rupture for a global catalog of large earthquake. Bull Seismol Soc Am 92:3309-3317. https://doi.org/10.1785/0120010293
Ogata Y (1983) Estimation of the parameters in the modified Omori formula for aftershock frequencies by the maximum likelihood procedure. J Phys Earth 31:115-124

Oth A (2013) On the characteristics of earthquake stress release variations in Japan. Earth Planet Sci Lett 377-378:132-141. https://doi.org/10.1016/j. epsl.2013.06.037

Sato T, Hirasawa T (1973) Body wave spectra from propagating shear cracks. J Phys Earth 21:415-431. https://doi.org/10.4294/jpe1952.21.415

Ueno H, Hatakeyama S, Aketagawa T et al (2002) Improvement of hypocenter determination procedures in the Japan meteorological agency. Q J Seism 65:123-134

Wessel P, Smith WHF (1998) New, improved version of generic mapping tools released. Eos, Trans Am Geophys Union 79:579-579. https://doi. org/10.1029/98EO00426

Yamada T, Mori JJ, Ide S et al (2005) Radiation efficiency and apparent stress of small earthquakes in a South African gold mine. J Geophys Res B Solid Earth 110:1-18. https://doi.org/10.1029/2004JB003221

Yoshida K, Hasegawa A, Okada T, linuma T (2014) Changes in the stress field after the 2008 M7.2 Iwate-Miyagi Nairiku earthquake in northeastern Japan. J Geophys Res Solid Earth 119:9016-9030. https://doi. org/10.1002/2014JB011291

Yoshida K, Hasegawa A, Okada T (2015a) Spatially heterogeneous stress field in the source area of the 2011 Mw 6.6 Fukushima-Hamadori earthquake, NE Japan, probably caused by static stress change. Geophys J Int 201:10621071. https://doi.org/10.1093/gji/ggv068

Yoshida K, Hasegawa A, Okada T (2015b) Spatial variation of stress orientations in NE Japan revealed by dense seismic observations. Tectonophysics 647:63-72. https://doi.org/10.1016/j.tecto.2015.02.013

Yoshida K, Hasegawa A, Okada T (2016a) Heterogeneous stress field in the source area of the 2003 M6.4 Northern Miyagi Prefecture, NE Japan, earthquake. Geophys J Int 206:408-419. https://doi.org/10.1093/gii/ ggw160

Yoshida K, Hasegawa A, Saito T et al (2016b) Stress rotations due to the M6.5 foreshock and M7.3 main shock in the 2016 Kumamoto, SW Japan, earthquake sequence. Geophys Res Lett. https://doi.org/10.1002/2016G L070581

Yoshida K, Saito T, Urata Y et al (2017) Temporal changes in stress drop, frictional strength, and earthquake size distribution in the 2011 YamagataFukushima, NE Japan, earthquake swarm, caused by fluid migration. J Geophys Res Solid Earth 122(79-10):397. https://doi.org/10.1002/2017j b014334

Yoshida K, Saito T, Emoto K et al (2019a) Rupture directivity, stress drop, and hypocenter migration of small- and moderate-sized earthquakes in the Yamagata-Fukushima border swarm triggered by upward pore-pressure migration after the 2011 Tohoku-Oki earthquake. Tectonophysics 769:228184

Yoshida K, Hasegawa A, Yoshida T, Matsuzawa T (2019b) Heterogeneities in stress and strength in tohoku and its relationship with earthquake sequences triggered by the 2011 M9 Tohoku-Oki earthquake. Pure Appl Geophys 176:1335-1355

Yukutake Y, lio Y, Katao H, Shibutani T (2007) Estimation of the stress field in the region of the 2000 Western Tottori Earthquake: using numerous aftershock focal mechanisms. J Geophys Res Solid Earth 112:1-13. https ://doi.org/10.1029/2005JB004250

\section{Publisher's Note}

Springer Nature remains neutral with regard to jurisdictional claims in published maps and institutional affiliations. 